\title{
JOURNAL OF DINDA
}

\author{
Kelompok Keahlian Rekayasa Data
}

Institut Teknologi Telkom Purwokerto

Vol. 1 No. 2 (2021) 82 - 87

ISSN Media Elektronik: -

\section{PENENTUAN JURUSAN SISWA SEKOLAH MENENGAH ATAS MENGGUNAKAN METODE FUZZY TSUKAMOTO}

\author{
Hikmah Quddustiani ${ }^{1}$, Ummi Athiyah ${ }^{2}$, Made Riza Kartika ${ }^{3}$, Rayhan Hidayat ${ }^{4}$, Luthfi Rakan Nabila ${ }^{5}$ \\ 1,2,3,4,5 Informatika, fakultas Informatika, institut Teknologi Telkom Purwokerto \\ ${ }^{1} 17102010 @$ ittelkom-pwt.ac.id, ${ }^{2}$ ummi@ittelkom-pwt.ac.id, \\ 317102013@ittelkom-pwt.ac.id, ${ }^{4} 17102042 @$ ittelkom-pwt.ac.id, ${ }^{5} 20110010 @$ ittelkom-pwt.ac.id
}

\begin{abstract}
According to the Regulation of the Minister of National Education (Permendiknas) Number 22 of 2006, the determination of majors is carried out at the end of the second semester of class $\mathrm{X}$ and the implementation of Teaching and Learning Activities (KBM) according to the program majors starts in the first semester of class XI. In fact, there are still many high school students who are confused about choosing a major in a tertiary institution and this phenomenon can be seen in high school students. There are several majors in high school programs such as Natural Sciences (IPA), Social Sciences (IPS), and Language. This research is expected to be able to determine the majors according to the abilities of the new students for the process of selecting majors and provide recommendations that help students in determining the majors in SMA using the Fuzzy Tsukamoto method. The Tsukamoto method is an extension of monotonous reasoning. In the Tsukamoto method, each consequence of the IF-THEN rules must be represented by a fuzzy set with monotonous membership functions assisted by system design using the programming language PHP, HTML, Javascript, and MySQL database, resulting in a decision-making system using the fuzzy method. tsukamoto which is a useful website for determining student majors so that it can lighten the work of the school in order to help speed up and make it easier for schools to make decisions in choosing majors.
\end{abstract}

Keywords: Fuzzy Tsukamoto, Decision Support Systems, High School, Website, Science, Social Sciences, Languages.

\begin{abstract}
Abstrak
Sesuai Peraturan Menteri Pendidikan Nasional (Permendiknas) Nomor 22 Tahun 2006, penentuan penjurusan dilaksanakan pada akhir semester dua kelas X dan pelaksanaan Kegiatan Belajar Mengajar (KBM) sesuai jurusan program dimulai pada semester satu kelas XI. Dalam kenyataannya masih banyak siswa SMA yang kebingungan dalam memilih jurusan pada Perguruan Tinggi dan pada fenomena ini terlihat pada Siswa SMA, Terdapat beberapa penjurusan pada program SMA seperti Ilmu Pengetahuan Alama (IPA), Ilmu Pengetahuan Sosial (IPS), dan Bahasa. penelitian ini diharapkan bisa menentukan jurusan sesuai dengan kemampuan yang dipunyai siswa baru untuk proses pemilihan jurusan dan memberikan rekomendasi yang membantu siswa/I dalam menentukan jurusan pada SMA menggunakan metode Fuzzy Tsukamoto. Metode Tsukamoto adalah perluasan dari penalaran monoton. Pada metode Tsukamoto, setiap konsekuen pada aturan yang berbentuk IFTHEN harus direpresentasikan dengan suatu himpunan fuzzy dengan fungsi keanggotaan yang monoton dengan dibantu perancangan sistem menggunakan bahasa pemrograman PHP, HTML, Javascript, dan juga database MySQL, menghasilkan sistem penentuan keputusan jurusan menggunakan metode fuzzy tsukamoto yang merupakan website berguna untuk mentukan jurusan siswa sehingga dapat meringankan kerja pihak sekolah agar membantu mempercepat dan memudahkan sekolah untuk menentukan keputusan dalam pemilihan jurusan.
\end{abstract}

Kata kunci: Fuzzy Tsukamoto, Sistem Pendukung Keputusan, SMA, Website, IPA, IPS, Bahasa.

(C) 2021 Jurnal DINDA

Diterima Redaksi : 27-01-2021 | Selesai Revisi : 26-04-2021 | Diterbitkan Online : 31-08-2021 


\section{Pendahuluan}

Sesuai Peraturan Menteri Pendidikan Nasional (Permendiknas) Nomor 22 Tahun 2006, penentuan penjurusan dilaksanakan pada akhir semester dua kelas $\mathrm{X}$ dan pelaksanaan Kegiatan Belajar Mengajar (KBM) sesuai jurusan program dimulai pada semester satu kelas XI[1]. Terdapat beberapa penjurusan pada program SMA seperti Ilmu Pengetahuan Alama (IPA), Ilmu Pengetahuan Sosial (IPS), dan Bahasa. Yang mana untuk penentuan jurusan siswa akan di ambil oleh sekolah dengan melewati beberapa pertimbangan salah satunya nilai raport pada semasa Sekolah Menengah Pertama (SMP). Penjurusan pada sekolah menengah ke atas memiliki tujuan antara lain mengelompokkan siswa sesuai kecakapan, kemampuan, bakat, dan minat yang relatif sama dengan membantu mempersiapkan siswa melanjutkan studi dan memilih dunia kerja, serta membantu memperkokoh keberhasilan dan kecocokan atas prestasi yang akan dicapai di waktu mendatang[2].Alasan diadakan penelitian ini dan (4). Pertanyaan tujuan. Dalam kenyataannya masih banyak siswa SMA yang kebingungan dalam memilih jurusan pada Perguruan Tinggi dan pada fenomena ini terlihat pada Siswa SMA, banyak siswa yang masih memilih jurusan berlandaskan keinginanya dan juga banyak yang hanya mengikuti temanya untuk bisa bersama selalu. Seharusnya kemampuan siswa SMA untuk menentukan jurusan di Perguruan Tinggi sesuai dengan minat dan kemampuannya ditentukan oleh sejauh mana informasi yang dimiliki tentang minat dan kemampuan akademis [3].

Maka dari itu penelitian ini diharapkan bisa menentukan jurusan sesuai dengan kemampuan yang dipunyai siswa baru untuk proses pemilihan jurusan dan memberikan rekomendasi pada pemilihan jurusan sesuai minat dan keinginan mengunakan metode logika fuzzy tsukamoto.

Bercermin dengan kekurangan diatas, penulis berusaha membantu siswa baru pada Sekolah Menengah Atas untuk menentukan jurusan yang akan diambilnya sesua dengan kemampuan. Dengan begitu kedepanya diharapkan permasalahan dalam pemilihan jurusan bisa diatasi. Maka dari itu penulis mengangkat judul "PENENTUAN JURUSAN SISWA SEKOLAH MENENGAH ATAS MENGGUNAKAN METODE FUZZY TSUKAMOTO"

2. Metode Penelitian

2.1 Perancangan Sistem
Sama dengan yang telah dijabarkan pada pendahluan, untuk penilaian akan menggunakan nilai-nilai beberapa mata pelajaran yang selanjutnya penilaian tersebut akan dijadikan faktor pada penetapan kelas dan himpunan fuzzy. Kemudian himpunan fuzzy akan dimasukan ke dalam beberapa kategori yaitu kurang, baik, dan bagus dan akan di jadikan kedalam input fuzzy tsukamoto.

\subsection{Analisa Kebutuhan Input}

Pada proses pengambilan keputusan input dilakukan menggunakan data nilai acak siswa SMP untuk melakukan uji coba.

\subsection{Analisis Kebutuhan Output}

Output yang akan didapatkan pada penelitian kali ini merupakan alternative yang akan mempunyai nilai tinggi dibandingkan alternative nilai yang lainya. Hasil output merupakan sebuah urutan alternative dari tinggi ke rendah, yang nantinya hasil akhir akan berasal dari nilai kriteria yang ada.

Penalmpilan urutan akan diawali dengan alternative tinggi ke alternative rendah yang dimaksudkan adalah alternative urutan kelas IPA, IPS dan Bahasa.

\section{Hasil dan Pembahasan}

\subsection{Flowchart Fuzzy Tsukamoto}

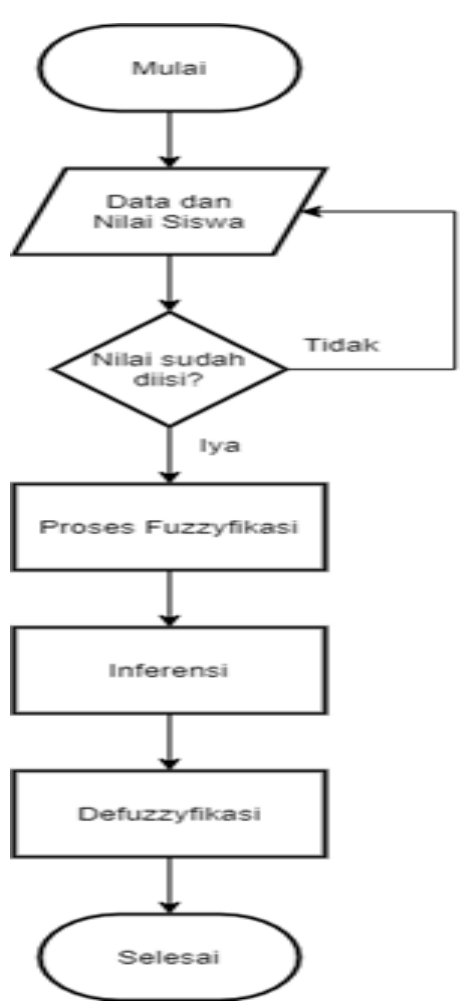

Journal of DINDA (Data Science, Information Technology, and Data Analtyics)

Vol. 1 No. 2 (2021) $82-87$ 


\subsection{Penyelesaian Dengan Fuzzy Tsukamoto}

Dengan melakukan pengambilan data siswa SMP secara acak yang dimana data tersebut berisi data diri dan data nilai siswa/I berdasarkan pilihan yang peneliti tentukan.

Tabel 3.1 Rentang Nilai Mata Pelajaran

\begin{tabular}{|l|l|}
\hline Mata Pelajaran & Range Nilai \\
\hline IPS & $0-100$ \\
\hline Bahasa & $0-100$ \\
\hline IPA & $0-100$ \\
\hline
\end{tabular}

Tabel 3.2 Contoh Kasus Inferensi Fuzzy

\begin{tabular}{|l|l|}
\hline Variabel Input & Nilai Input \\
\hline IPS & 65 \\
\hline Bahasa & 82 \\
\hline IPA & 75 \\
\hline
\end{tabular}

\subsection{Fungsi Keanggotaan Nilai}

Fungsi pada derajat linier yang turun akan memperentasikan himpunan fuzzy kurang, fungsi derajat linier segitiga akan mempesentasikan himpunan fuzzy baik, dan fungsi derajat linier yang naik akan mempresentasikan himpunan fuzzy bagus.

\subsubsection{IPS}

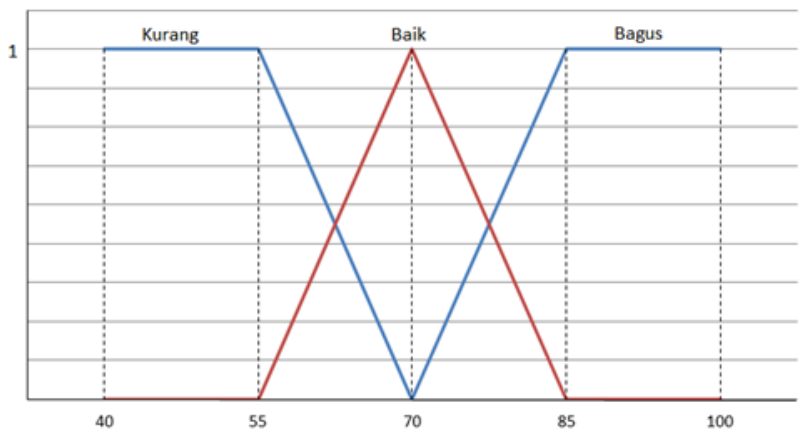

Derajat Kenggotaan IPS Kurang

$$
\begin{aligned}
& \frac{(X-40)}{(55-40)} ; 40 \leq x \leq 55 \\
& \frac{1}{(70-x)} ; \mathrm{x}=55 \\
& \frac{(70-55)}{(70 \leq x \leq 70} \\
& 0 \quad ; \mathrm{x}<40 \text { atau } \mathrm{x}>70
\end{aligned}
$$

Derajat Keanggotaan IPS Baik

$$
\begin{aligned}
& \frac{(x-55)}{(70-55)} ; 55 \leq x \leq 70 \\
& 1 \quad ; \mathrm{x}=70 \\
& \frac{(85-x)}{(85-70)} ; 70 \leq x \leq 85 \\
& 0 \quad ; \mathrm{x}<55 \text { atau } \mathrm{x}>85
\end{aligned}
$$

Derajat Keanggotaan IPS Bagus

$$
\begin{aligned}
& \frac{(x-70)}{(100-85)} ; 70 \leq x \leq 85 \\
& 1 \quad ; x=85 \\
& \frac{(100-x)}{(100-85)} ; 85 \leq x \leq 180 \\
& 0 \quad ; x<55 \text { atau } \mathrm{x}>85
\end{aligned}
$$

\subsubsection{IPA}

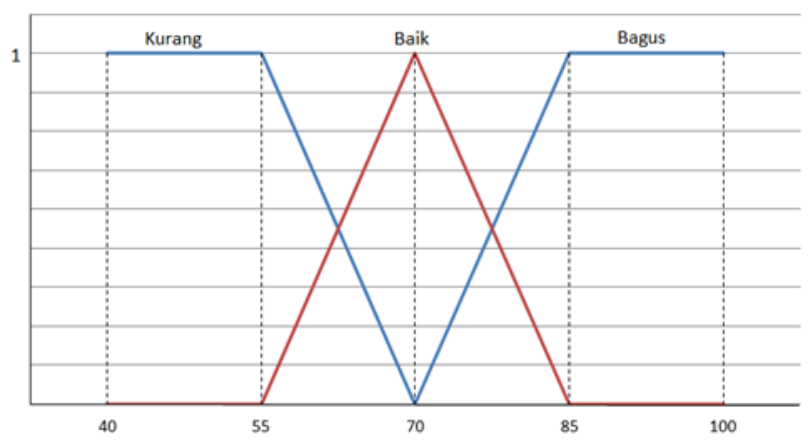

Derajat Kenggotaan IPA Kurang

$$
\begin{aligned}
& \frac{(X-40)}{(55-40)} ; 40 \leq x \leq 55 \\
& 1 ; \mathrm{x}=55 \\
& \frac{(70-x)}{(70-55)} ; 55 \leq x \leq 70 \\
& 0 \quad ; \mathrm{x}<40 \text { atau } \mathrm{x}>70
\end{aligned}
$$

Derajat Keanggotaan IPA Baik

$$
\begin{aligned}
& \frac{(x-55)}{(70-55)} ; 55 \leq x \leq 70 \\
& 1 \quad ; \mathrm{x}=70 \\
& \frac{(85-x)}{(85-70)} ; 70 \leq x \leq 85 \\
& 0 \quad ; \mathrm{x}<55 \text { atau } \mathrm{x}>85
\end{aligned}
$$

Derajat Keanggotaan IPA Bagus

$$
\begin{gathered}
\frac{(x-70)}{(100-85)} ; 70 \leq x \leq 85 \\
1 \quad ; x=85
\end{gathered}
$$

Journal of DINDA (Data Science, Information Technology, and Data Analtyics) Vol. 1 No. 2 (2021) $82-87$ 


$$
\begin{aligned}
& \frac{(100-x)}{(100-85)} ; 85 \leq x \leq 180 \\
& 0 \quad ; \mathrm{x}<55 \text { atau } \mathrm{x}>85
\end{aligned}
$$

\subsubsection{Bahasa}

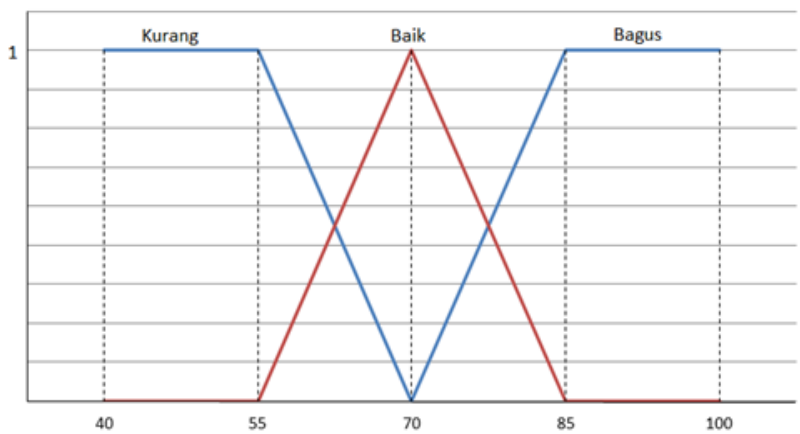

Derajat Kenggotaan Bahasa Kurang

$$
\begin{aligned}
& \frac{(X-40)}{(55-40)} ; 40 \leq x \leq 55 \\
& 1 ; \mathrm{x}=55 \\
& \frac{(70-x)}{(70-55)} ; 55 \leq x \leq 70 \\
& 0 \quad ; \mathrm{x}<40 \text { atau } \mathrm{x}>70
\end{aligned}
$$

Derajat Keanggotaan Bahasa Baik

$$
\begin{aligned}
& \frac{(x-55)}{(70-55)} ; 55 \leq x \leq 70 \\
& 1 \quad ; \mathrm{x}=70 \\
& \frac{(85-x)}{(85-70)} ; 70 \leq x \leq 85 \\
& 0 \quad ; \mathrm{x}<55 \text { atau } \mathrm{x}>85
\end{aligned}
$$

Derajat Keanggotaan IPA Bagus

$$
\begin{aligned}
& \frac{(x-70)}{(100-85)} ; 70 \leq x \leq 85 \\
& 1 ; \mathrm{x}=85 \\
& \frac{(100-x)}{(100-85)} ; 85 \leq x \leq 180 \\
& 0 \quad ; \mathrm{x}<55 \text { atau } \mathrm{x}>85
\end{aligned}
$$

\subsection{Rule}

[R1] IF Bahasa cukup AND IPS Sangat Baik AND IPA cukup THEN IPS

[R2] IF Bahasa cukup AND IPS cukup AND IPA cukup THEN IPS

[R3] IF Bahasa cukup AND IPS cukup AND IPA sangat baik THEN IPA

[R4] IF Bahasa cukup AND IPS baik AND IPA cukup THEN IPS

[R5] IF Bahasa cukup AND IPS baik AND IPA baik THEN IPA
[R6] IF Bahasa cukup AND IPS baik AND IPA sangat baik THEN IPA

[R7] IF Bahasa cukup AND IPS sangat baik AND IPA cukup THEN IPS

[R8] IF Bahasa cukup AND IPS sangat baik AND IPA baik THEN IPA

[R9] IF Bahasa cukup AND IPS sangat baik AND IPA sangat baik THEN IPA

[R10] IF Bahasa baik AND IPS cukup AND IPA cukup THEN Bahasa

[R11] IF Bahasa baik AND IPS cukup AND IPA baik THEN Bahasa

[R12] IF Bahasa baik AND IPS cukup IPA Sangat baik THEN IPA

[R13] IF Bahasa baik AND IPS baik AND IPA baik THEN IPS

[R14] IF Bahasa baik AND IPS baik AND IPA cukup THEN IPS

[R15] IF Bahasa baik AND IPS baik AND IPA sangat baik THEN IPA

[R16] IF Bahasa baik AND IPS sangat baik AND IPA cukup THEN IPS

[R17] IF Bahasa baik AND IPS sangat baik AND IPA baik THEN IPS

[R18] IF Bahasa baik AND IPS sangat baik AND Bahasa sangat baik THEN IPA

[R19] IF Bahasa sangat baik AND IPS cukup AND IPA cukup THEN Bahasa

[R20] IF Bahasa sangat baik AND IPS cukup AND IPA baik THEN Bahasa

[R21] IF Bahasa sangat baik AND IPS cukup AND IPA sangat baik THEN Bahasa

[R22] IF Bahasa sangat baik AND IPS baik AND IPA cukup THEN Bahasa

[R23] IF Bahasa sangat baik AND IPS baik AND IPA baik THEN Bahasa

[R24] IF Bahasa sangat baik AND IPS baik AND IPA sangat baik THEN Bahasa

[R25] IF Bahasa sangat baik AND IPS sangat baik AND IPA cukup THEN Bahasa

[R26] IF Bahasa sangat baik AND IPS sangat baik AND IPA baik THEN IPS

[R27] IF Bahasa sangat baik AND IPS sangat baik AND IPA sangat baik THEN IPA

\subsection{Perancangan Sistem}

3.5.1 Use Case Diagram

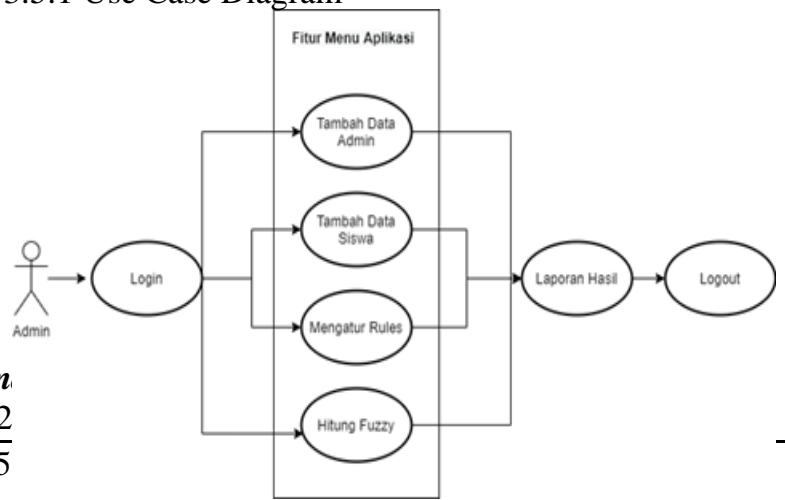




\subsubsection{Rancangan Program}

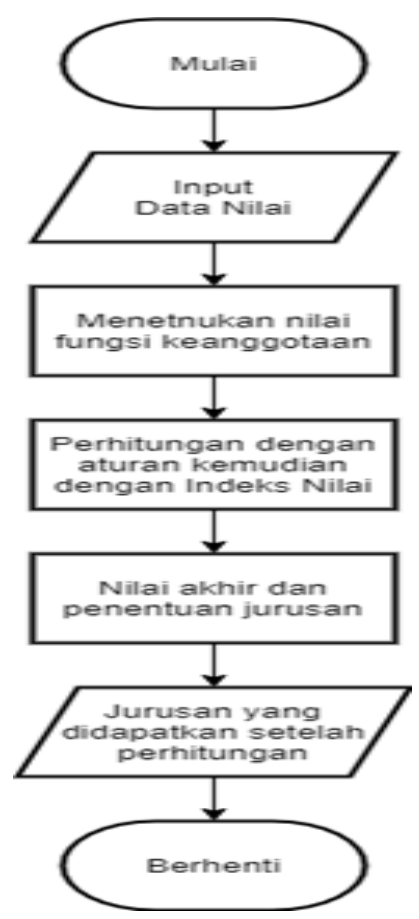

3.6 Implementasi

Implementasi dari penelitian ini nantinya akan dirancang sebuah aplikasi berbasis web yang dapat digunakan untuk menentukan jurusan dengan perhitungan fuzzy tsukamoto.

\section{Kesimpulan}

Berdasarkan hasil dan impementasi system yang telah dilakukan penelti, dan didapatkan kesimpulan : a. Sistem pendukung keputusan untuk penentuan pada jurusan SMA dengan metode tsukamoto yang telah dirancang bisa membantu mempercepat dan memudahkan sekolah untuk menentukan keputusan dalam pelimilihan jurusan.

b. Implementasi jurusan telah berhasil dibangun menggunakan menggunakan bahasa pemrograman PHP dan dengan metode fuzzy tsukamoto.

c. Sistem bisa melakukan penentuan juruan menggunakan hasil nilai pada Ujian Akhir Sekolah, dengan menggunakan tiga mata pelajaran antara lain: IPA, IPS, dan Bahasa.

d. Pada proses penentuan jurusan menggunakan metode fuzzy tsukamoto akan menentukan hasil output keputusan tiga jurusan antara lain : IPA, IPS, dan Bahasa.

\section{Saran}

Dengan kesimpulan diaas saran yang dapat di sampaikan untuk pengembangan sistem penentuan selanjutnya sebagai berikut :

a. Bisa melakukan pengembangan pada sistem yang telah dibuat dengan cara menambahkan jumlah input mata pelajaran dengan menyesuaikan nilai Ujian Nasional SMP.

b. Diharapkan kedepanya sistem penentuan juruan kedepanya dapat diakses dengan aplikasi mobile.

c. Belum adanya keamanan sistem untuk data siswa, yang ditakutka hal yang tidak diinginkan terjadi.

\section{Daftar Rujukan}

[1] M. A. Sasongko, L. Linawati, and H. A. Parhusip, "Penentuan Penjurusan Program Peserta Didik Tingkat SMA Menggunakan Fuzzy C-Means dan Fuzzy Inference System Mamdani," pp. 706-717, 2013.

[2] D. N. Handayani, F. N. Hakim, and A. Solechan, "Sistem Pendukung Keputusan Untuk Pemilihan Jurusan Menggunakan Fuzzy Multiple Atribute Decision Making Dengan Metode Simple Additive Weighting Studi Kasus Pada Sma Islam Sultan Agung 1 Semarang," J. Transform., vol. 11, no. 2, p. 69, 2014, doi: 10.26623/transformatika.v11i2.98.

[3] Ferdinandus and I. luvi I. Astutik, "Sistem pendukung keputusan untuk membantu siswa sma kelas xii dalam menentukan jurusan di perguruan tinggi dengan menggunakan logika fuzzy metode mamdani," Sist. Nas. "Inovasi dalam Desain dan Teknol., pp. 158-168, 2015.

[4] D. I. Smk and N. Makassar, "Fakultas Keguruan dan Ilmu Pendidikan, Universitas Muhammadiyah 
Makassar," 2018.

[5] T. Marchwinski, "EconomiC impact of existing and new commuter rail service on retail and recreational spending in the vicinity of station areas," Transp. Res. Rec., vol. 2008, no. 1623, pp. 135-143, 1998, doi: 10.3141/1623-18.

[6] Y. Ferdiansyah and N. Hidayat, "Implementasi Metode Fuzzy - Tsukamoto Untuk Diagnosis Penyakit Pada Kelamin Laki Laki," J. Pengemb. Teknol. Inf. dan Ilmu Komput., vol. 2, no. 12, pp. 7516-7520, 2018.

[7] A. A. Caraka, H. Haryanto, D. P. Kusumaningrum, S. Astuti, F. I. Komputer, and U. D. Nuswantoro, "Logika Fuzzy Menggunakan Metode Tsukamoto Untuk Prediksi Perilaku Konsumen Di Toko Bangunan," Techno.COM, vol. 14, no. 4, pp. 255265, 2015, [Online]. Available: http://publikasi.dinus.ac.id/index.php/technoc/article /view/970. 